\title{
Multiple regulation of carp (Cyprinus carpio L.) macrophages and neutrophilic granulocytes by serum factors: influence of infection with atypical Aeromonas salmonicida
}

\author{
B.M.L. Verburg-van Kemenade ${ }^{\mathrm{a}, *}$, J.G. Daly ${ }^{\mathrm{b}}$, \\ A. Groeneveld ${ }^{a}$, G.F. Wiegertjes ${ }^{a}$ \\ a Department of Experimental Animal Morphology and Cell Biology, Wageningen Agricultural University, \\ P.O. Box 338,6700 AH Wageningen, Netherlands \\ ${ }^{b}$ Division of Natural Sciences, Purchase College. State University of New York, 735 Anderson Hill Road, \\ Purchase, NY 10577, USA
}

Accepted 10 July 1995

\begin{abstract}
Normal carp serum contains inhibitory and stimulatory factors for macrophage and neutrophilic granulocyte respiratory burst activity. As stimulatory factors were only effective in combination with phorbol myristate actetate (PMA) activation, it is concluded that they are probably linked to protein kinase $\mathrm{C}$ activation. Both the stimulatory and inhibitory factors are heat stable.

Macrophage- and neutrophilic granulocyte-enriched cell fractions from the pronephros of carp had high respiratory burst- and high bactericidal in vitro responses to virulent atypical Aeromonas salmonicida bacteria. Serum factors were inhibitory for the A. salmonicida induced respiratory burst activity. No change in inhibitory or stimulatory serum factors could be observed during a 12-day challenge experiment with A. salmonicida, or during a rechallenge of survivors from a previous sub-lethal infection. The sensitivity of macrophages and neutrophilic granulocytes to stimulation of respiratory burst activity by PMA was not significantly altered.

Culture supernatants from PHA pre-treated lymphocytes stimulated the respiratory burst activity of macrophages and neutrophilic granulocytes suggesting that serum factors may partially be lymphocyte derived.
\end{abstract}

\footnotetext{
* Corresponding author. Tel.: +31.8370.82669, +31.8370.83509; Fax: +31.8370.83962; email: Lidy. Verburg@celb.EDC.WAU.NL.
} 
Carp macrophages and neutrophilic granulocytes undergo a multiple regulation by stimulatory and inhibitory factors that will probably prevent the cells from causing tissue damage during latent periods, but which enables rapid reaction when fast induction of activity is required.

Keyuords: Carp; Macrophages; Neutrophilic granulocytes: Respiratory burst: Microbicidal activity: Macrophage activating factor: Serum factors. Aeromonas salmonicida

\section{Introduction}

Erythrodermatitis of carp, Cyprinus carpio L. is an ulcerative disease caused by atypical strains of the bacterium Aeromonas salmonicida (Bootsma et al., 1977; McCarthy and Roberts, 1980). Recently, it was discovered that carp that had received an in vitro, sub-lethal infection of erythrodermatitis, were protected from subsequent lethal infections (Daly et al., 1994). The protection lasted for at least 5 months, but the mechanisms responsible remain unspecified. Preliminary results indicated that transfer of immune serum from recovered animals did not protect naive carp (J.E. Daly et al.. unpublished observations). Although phagocyte responses are anticipated to be short lived, carp macrophages and/or neutrophilic granulocytes could play a role in the observed protection. Recently, in rainbow trout (Oncorhynchus mykiss), it was shown that immunization with killed $A$. salmonicida induced a lymphocyte-derived release of macrophage-activating factors, with peak responses occurring 4-5 weeks post-immunization (Marsden et al., 1994). Lymphocyte proliferation peaked 1-2 weeks post-immunization, indicating a role for the macrophages in the survival value of these animals.

In the present study we focus on the possible influence of serum-derived macrophage activating factors, and on the role of the phagocyte-regulated mechanisms of defence, in sustained protection. Previously, we have been able to isolate enriched fractions of macrophages and neutrophilic granulocytes from carp pronephros tissue, and were able to determine the activation of respiratory burst reaction through measurement of the production of superoxide anions and hydrogen peroxide (Verburg- van Kemenade et al.. 1994). In the present in vitro study we reveal that a lymphocyte-derived macrophageactivating factor may be active in carp. Subsequently. we investigated the presence of factors in normal serum regulating the respiratory burst activity. To examine the possible role of these factors in the recovery of carp protected by a sub-lethal infection, we followed the activity of the pronephros macrophages, neutrophilic granulocytes, and the peripheral blood leucocytes during the course of a rechallenge with atypical A. salmonicida. To elucidate the involvement of macrophage activating factors in the serum of re-challenged animals, the effect of immune serum on the respiratory burst activity was investigated at several time points post-infection.

\section{Materials and methods}

\subsection{Animals}

Common carp (Cyprinus carpio L.), strain R3 $\times$ R8, 12 months of age and weighing approximately $180 \mathrm{~g}$, were raised in a system with recirculating ultraviolet light-steri- 
lized water at $23^{\circ} \mathrm{C}$, and fed daily with pelleted dry food (Trouvit, Trouw, Putten, The Netherlands). Before challenge with $A$. salmonicida, carp were acclimatized to a flow-through challenge-unit, consisting of separate aquaria with an independent supply of tap water at $20^{\circ} \mathrm{C}$, for at least 2 weeks. Fish were anesthetized in buffered tricaine methane sulphonate $(0.02 \% \mathrm{v} / \mathrm{v}$, Crescent Research Chemicals, Phoenix, AZ). Blood was collected by puncture of the caudal vein prior to dissection of pronephros tissue.

\subsection{Serum}

Serum pooled from ten carp was used as a standard serum sample (pooled carp serum; PCS). Heat inactivation was performed at $55^{\circ} \mathrm{C}$ for $10 \mathrm{~min}$ (Yano et al., 1984). Immune serum was obtained from carp that had recovered from a sub-lethal bath challenge with atypical A. salmonicida. Immune sera had increased antibody titres as measured by agglutination of a non-autoagglutinating typical $A$. salmonicida strain (TG36 ${ }^{-}$), as described by Daly et al. (1994).

\subsection{Aeromonas salmonicida}

Aeromonas salmonicida V234/81 (Evenberg et al., 1985), a virulent atypical strain, was grown on blood agar, inoculated on broth, and subsequently grown at $20^{\circ} \mathrm{C}$ for $48 \mathrm{~h}$, as described previously (Daly et al., 1994). The bacteria were collected by centrifugation, washed and diluted in RPMI medium, which, for all experiments, was adjusted to carp osmolarity (270 mOsmol $\mathrm{kg}^{-1}$, cRPMI), prior to their use for stimulation of respiratory burst activity.

To study the influence of infection on immune cells and serum, three groups of 12 animals were given either a sham treatment, a first lethal challenge, or a rechallenge with $A$. salmonicida. Lethal bath challenge was performed as described previously (Daly et al., 1994). Briefly, animals were immersed for $30 \mathrm{~min}$ in aerated water containing $2 \times 10^{6} \mathrm{~A}$. salmonicida $\mathrm{ml}^{-1}$. To assure a better access of bacteria one scale was removed. Based upon previous experiments, with this infective dose an average mortality of $50 \%$ could be expected after a 2-3 week period. To obtain animals with a sustained protection, a sub-lethal bath challenge $\left(10^{4}\right.$ bacteria $\left.\mathrm{ml}^{-1}\right)$ was given 6 weeks prior to the lethal challenge (re-challenge). Control fish were treated similarly, except for the addition of bacteria. Every second day two animals from each group were sacrificed for testing.

\subsection{Isolation and culture of pronephros macrophages and neutrophilic granulocytes}

Only siliconized glass or polypropylene was used for the isolation procedure (Sigmacoat, Sigma, St. Louis, MO, USA). Pronephros cell suspensions were prepared by passing rinsed tissue through a $50 \mu \mathrm{m}$ nylon mesh in cRPMI medium. The cells were washed and separated on a discontinuous Percoll gradient. Macrophage-enriched (density range $1.02-1.07 \mathrm{~g} \mathrm{~cm}^{-3}$ ) and neutrophilic granulocyte-enriched fractions (density range $1.07-1.08 \mathrm{~g} \mathrm{~cm}^{-3}$ ) were collected. Analysis of these cell fractions has been described earlier (Bayne, 1986; Temmink and Bayne, 1987; Verburg-van Kemenade et 
al., 1994). The cell fractions were washed, adjusted to a cell density of $10^{7}$ leucocytes $\mathrm{ml}^{-1}$, and allowed to adhere for $1 \mathrm{~h}\left(26^{\circ} \mathrm{C}, 5 \% \mathrm{CO}_{2}\right)$ in 96 -well microtitre plates (100 $\mu l$ per well). The supernatant was removed, and the adhering cells were washed three times with medium. Monolayers of both cell fractions were cultured in cRPMI medium supplemented with $0.5 \%(\mathrm{v} / \mathrm{v})$ pooled carp serum, Penicillin-G $\left(100 \mathrm{IU} \mathrm{ml}^{-1}\right.$, Sigma, St. Louis, MO, USA), Streptomycin sulphate (50 $\mathrm{mg}^{-1}$. Serva, Heidelberg, Germany) and L-glutamine (2.0 mM) (RPMI ${ }^{++}$).

\subsection{Respiratory burst activity}

In vitro respiratory burst activity was determined with the nitro blue tetrazolium (NBT) reduction assay based on the methods of Pick and Mizel (1981) as described earlier (Verburg-van Kemenade et al., 1994). Quadruplicate monolayers of $10^{6}$ cells of either fraction were prepared. After $1 \mathrm{~h}$, non-adhering cells were removed by rinsing three times with cRPMI without phenol red. Monolayers, with or without stimuli, were incubated for $90 \mathrm{~min}$ at $26^{\circ} \mathrm{C}$ under $5 \% \mathrm{CO}_{2}$ in $1 \mathrm{mg} \mathrm{ml}^{-1} \mathrm{NBT}$, dissolved in cRPMI medium without phenol red. The medium was subsequently removed, the monolayers washed, and the cells fixed in $100 \%$ methanol. Finally, the monolayers were washed three times in $70 \%$ methanol and allowed to air dry. The formazan in each well was dissolved in $120 \mu \mathrm{l} 2 \mathrm{M} \mathrm{KOH}$ and $140 \mu \mathrm{l}$ dimethylsulphoxide (DMSO). After mixing, the optical density was read in a multiscan reader (Anthos $2001 / 1$, Salzburg, Austria) at $690 \mathrm{~nm}$ with reference to $430 \mathrm{~nm}$ against a blank without cells. The percentage of adhering cells per well was determined by counting nuclei in a haemocytometer, 2 min after cell lysis and subsequent to staining in $0.1 \mathrm{M}$ citric acid, $1 \%(\mathrm{w} / \mathrm{v})$ Tween 20 (Merck, Darmstadt, Germany), $0.5 \%$ (v/v) Crystal Violet (Merck). Optional, the respiratory burst activity was stimulated during the assay with $0.1 \mu \mathrm{g} \mathrm{ml}^{-1}$ phorbolmyristate-acetate (PMA: Signla, St. Louis, MO, USA).

\subsection{Bactericidal activity}

In vitro bactericidal activity was measured by spectrophotometric analysis based on the method developed by Graham et al. (1988). Triplicate monolayers of adherent cells were incubated with a serial dilution of opsonized ( $1 \mathrm{~h} 50 \%$ PCS) A. salmonicida bacteria in CRPMI medium. After shaking for $20 \mathrm{~s}$ the plate was centrifuged at $150 \mathrm{~g}$ for $5 \mathrm{~min}$ and subsequently incubated for 0,2 and $4 \mathrm{~h}$. After incubation, the plates were centrifuged, the supernatant carefully removed and the adherent cells lysed in $50 \mu \mathrm{l}$ $0.5 \%$ Tween 20 (Merck. Darmstadt, Germany). Next, $100 \mu l$ of Tryptic Soy Broth (Difco, Detroit, MI, USA) was added, followed by incubation of the plate for $16 \mathrm{~h}$ at $20^{\circ} \mathrm{C}$. Subsequently, $25 \mu \mathrm{l}$ of cold 3[4,5-di-methylthiazol-2yl] 2,5-diphenyltetrazolium bromide (MTT) $\left(2.1 \mathrm{mg} \mathrm{ml}^{-1}\right.$. Sigma, St. Louis, MO, USA) was added to each well. After $15 \mathrm{~min}$ incubation, the optical density was read at $600 \mathrm{~nm}$ in a multiscan reader.

\subsection{Isolation and culture of peripheral blood lymphocytes}

Freshly collected blood, diluted once with cRPMI medium to which $50 \mathrm{IU} \mathrm{mI}^{-1}$ of heparin (Leo Pharmaceutical Products. Weesp, The Netherlands) had been added, was 
allowed to settle for $1 \mathrm{~h}$ at $4^{\circ} \mathrm{C}$. After centrifugation (15 min, $300 \mathrm{~g}$, no brake), leucocytes were collected and layered onto 1.5 volumes of Lymphoprep (density $1.077 \mathrm{~g}$ $\mathrm{ml}^{-1}$, Nycomed, Breda, Netherlands). Following $30 \mathrm{~min}$ centrifugation at $700 \mathrm{~g}$, the lymphocyte layer was collected, washed three times and the final suspension adjusted to $10^{7}$ cells $\mathrm{ml}^{-1}$.

\subsection{Lymphokine supernatant}

Following isolation, $10^{7}$ lymphocytes $\mathrm{ml}^{-1}$ were stimulated for $4 \mathrm{~h}$ in cRPMI medium without PCS, supplemented with $10 \mu \mathrm{g} \mathrm{m}{ }^{-1}$ phytohaemagglutinin (PHA; Difco, Detroit, MI, USA). The PHA was washed away three times with cRPMI and the lymphocytes were cultured for 3 days in $\mathrm{CRPMI}^{++}$with $0.5 \%$ PCS.

\subsection{Lymphocyte proliferation}

At each time point of Aeromonas infection, lymphocytes were taken from two individuals and were cultured separately in 96-well microtitre plates for $72 \mathrm{~h}$ in $200 \mu \mathrm{l}$

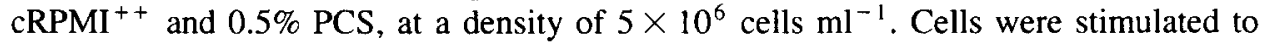
proliferate with $10 \mu \mathrm{g} \mathrm{ml}^{-1}$ PHA (Difco, Detroit, MI, USA) in the presence of $10^{-5} \mathrm{M}$ $\beta$-mercaptoethanol. Next, the cell cultures were labelled with $185 \mathrm{kBq} \mathrm{ml}^{-1}{ }^{\beta} \mathrm{H}$-methyl thymidine (Amersham, UK) for $16 \mathrm{~h}$. The content of each well was harvested with a Skatron semi-automatic cell harvester (Lier, Norway). The filters with the retained cells were dried for $1 \mathrm{~h}$ at $50^{\circ} \mathrm{C}$ and the filters were counted in a Beckman LS 1701 scintillation counter using Beckman Ready Safe Scintillation fluid (Beckman, Fullerton, CA, USA).

\section{Results}

\subsection{Activation of macrophages, neutrophilic granulocytes and lymphocytes}

In vitro, A. salmonicida was able to induce a significant dose-dependent stimulation of NBT reduction by macrophages and neutrophilic granulocytes. The stimulation equalled the effect that was obtained by optimal stimulation of protein kinase $\mathrm{C}$ with the phorbol ester, phorbolmyristate acetate (PMA) (see Fig. 1). Although both macrophages and neutrophilic granulocytes were able to kill A. salmonicida (Fig. 2), in comparison, neutrophilic granulocytes generally performed the faster in vitro microbicidal activity.

During a first lethal challenge or re-challenge with $A$. salmonicida, the macrophageand neutrophilic granulocyte cell fractions that were isolated from head kidneys over a 12-day period had no significant differences in basal respiratory burst activity. Although an enhanced sensitivity to PMA activation was measured for cells from re-challenged animals, the differences with cells from both sham treated or first challenged fish were not significant owing to large fish-to-fish variation in response (data not shown).

In vitro, lymphocyte proliferation was assessed in a PHA stimulation assay with peripheral blood lymphocytes from the control, the challenged and the re-challenged 


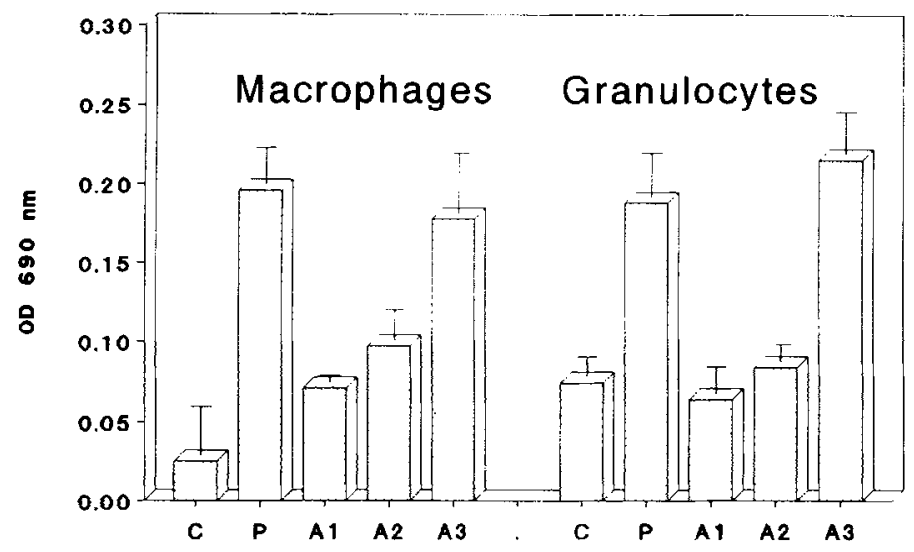

Fig. 1. In vitro induction of intracellular $\mathrm{O}_{2}$ formation in macrophage- and neutrophilic granulocyte-enriched pronephros cell fractions from carp, through spectrophotometric measurement of NBT reduction. Values are means $\pm S D$ of quadruplicate measurements. $C$, basal NBT reduction; P, PMA induced reaction; Al-3. dose-response relationship of stimulation by the virulent atypical strain of Aeromonas salmonicida $\mathrm{V} 234 / 81$. l, $10^{8}$ bacteria $\mathrm{ml}^{-1} ; 2,10^{9}$ bacteria $\mathrm{ml}^{-1}, 3,10^{10}$ bacteria $\mathrm{ml}^{-1}$.

fish. During the 12-day infection, no significant difference in activity of the PHA stimulated lymphocytes was found (data not shown).

\subsection{Activating and inactivating factors}

\subsubsection{Lymphocyte-derived activating factors}

When serial dilutions ( $1 / 2$ to 1/64) of 3-day culture supernatant of PHA pre-stimulated lymphocytes were co-cultured with macrophages or neutrophilic granulocytes for
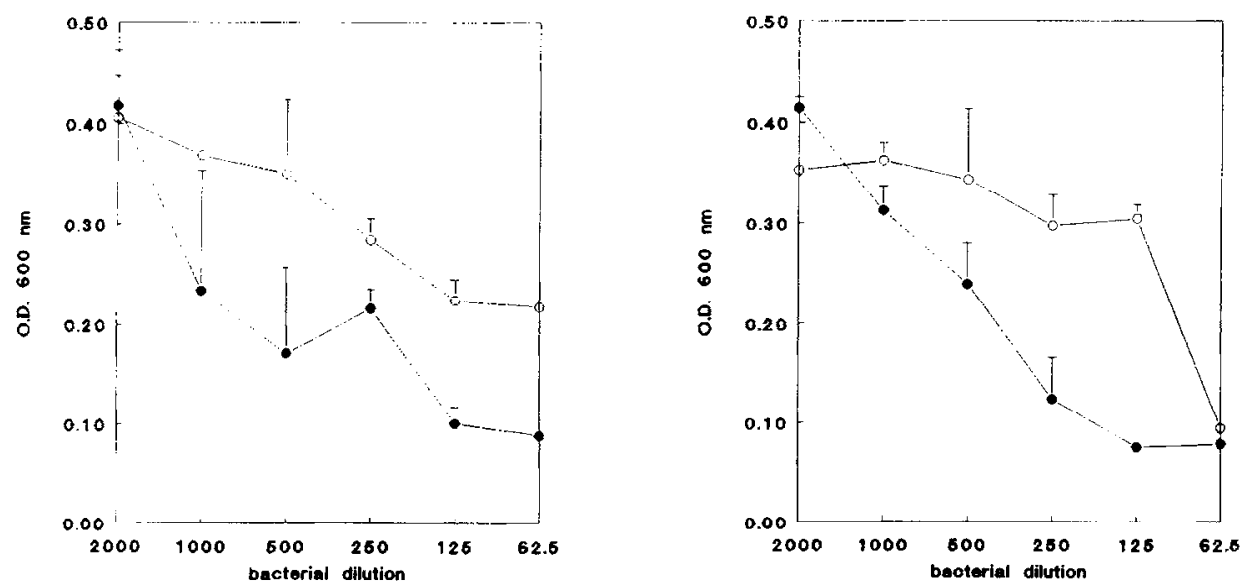

Fig. 2. In vitro killing of Aeromonas salmoniciela $V 234 / 81$ by macrophagc-enriched and granulocyte-enriched cell fractions of pronephros, through measurement of $\mathrm{MTT}$ reduction at $600 \mathrm{~nm}$. Control reaction of cells and bacteria, without incubation; $O 3 \mathrm{~h}$ incubation of cells with bacteria. Values are means $\pm S D$ of triplicate measurements. 

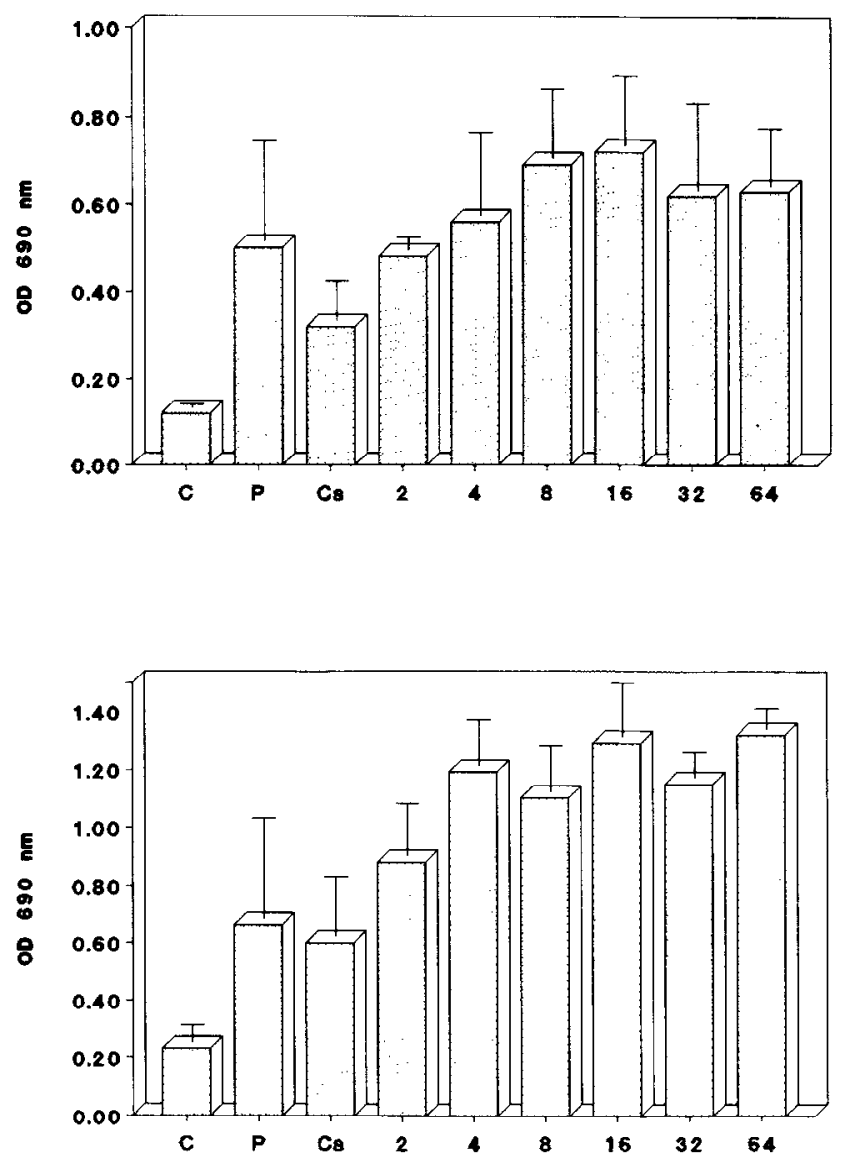

Fig. 3. Effect of culture supernatants of pre(PHA)-stimulated lymphocytes on NBT reduction of PMA-stimulated macrophage- (a) and neutrophilic granulocyte (b) cell fractions from pronephros cell suspension. $C$, basal NBT reduction; $P$, stimulation with $0.1 \mu \mathrm{g} \mathrm{ml^{-1 }}$ PMA; Cs, NBT reduction with PMA stimulation and supplementation with $50 \%$ culture medium of unstimulated lymphocytes; 2-64, NBT reduction with PMA stimulation and supplementation with two-fold dilutions of culture medium from PHA pre-stimulated lymphocytes. Values are means \pm SEM of quadruplicate measurements.

$48 \mathrm{~h}$, a dose-dependent greater sensitivity to PMA stimulation of the respiratory burst activity was induced (Fig. 3 ).

\subsubsection{Serum factors}

The addition of pooled carp serum (PCS) to the macrophage and neutrophilic granulocyte cell fractions resulted in a dose-dependent decrease of basal respiratory burst activity in both fractions. Depending on the concentration of PCS added, the decrease varied from $5-30 \%$ ( $0.5 \%$ PCS) to $50 \%-90 \%$ (5\% PCS). However, when cells were concomitantly activated with phorbol ester (PMA), serum addition induced a synergistic stimulation of the respiratory burst activity. Again, the degree of stimulation 


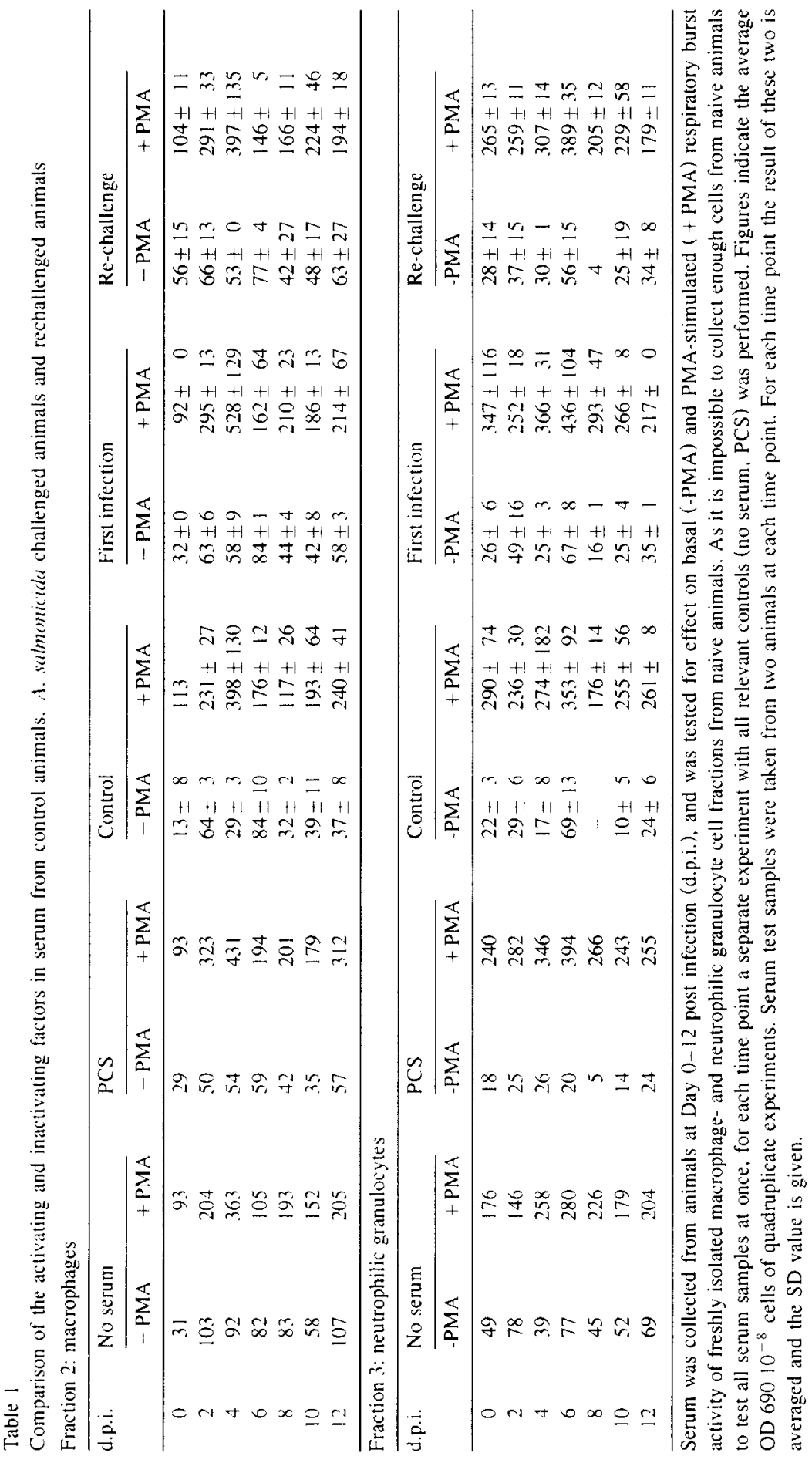




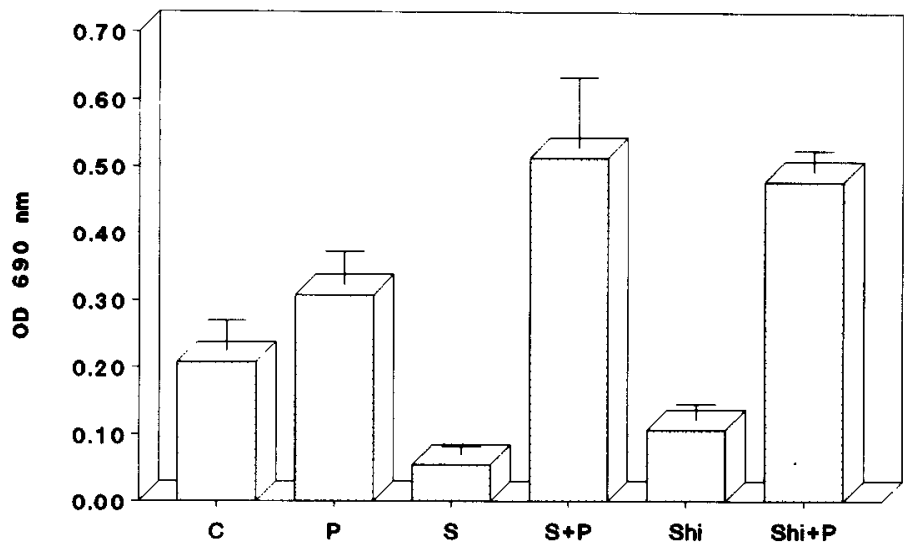

Fig. 4. Effect of pooled carp serum on NBT reduction in macrophage cell fractions of pronephros cells. C, control incubation; $\mathrm{P}$, stimulation with $0.1 \mu \mathrm{g} \mathrm{ml^{-1 }} \mathrm{PMA} ; \mathrm{S}$, incubation with $5 \% \mathrm{v} / \mathrm{v} \mathrm{PCS} ; \mathrm{S}+\mathrm{P}$, incubation in the presence of PCS and PMA; Shi, incubation with $5 \% \mathrm{v} / \mathrm{v}$ heat-inactivated PCS; Shi $+\mathrm{P}$, incubation with $5 \% \mathrm{v} / \mathrm{v}$ heat-inactivated PCS and PMA. Values are means \pm SD of quadruplicate measurements.

depended on the concentration of PCS. When $0.5 \%$ PCS was added, only a slight stimulation of the respiratory burst activity was seen ( $10 \%$ on average). The maximal synergistic stimulatory effect, depending on the inhibitory factors present, was seen at a 2.5-5\% concentration of PCS. Both the inhibitory and the stimulatory factors were heat stable (Fig. 4).

To investigate a possible stimulatory and/or inhibitory effect of serum addition on the activation of the respiratory burst by $A$. salmonicida, $0.5-5 \%$ PCS was added to phagocytes. The addition of serum reduced the activation by the bacterium of the respiratory burst in both macrophages and neutrophilic granulocytes (Fig. 5). Again heat inactivation hardly altered the effect.

In order to detect a possible relationship between serum activity and immune response, we tested the inhibitory and stimulatory effects of sera isolated from carp undergoing an infection with $A$. salmonicida (first challenge or re-challenge) on the respiratory burst- and on the lymphocyte proliferation activity. In general, the inhibitory effect on respiratory burst activity remained present in all sera, and no sign of a synergistic stimulation by bacteria and serum was observed (Table 1). Moreover, the synergism obtained in the presence of PMA was equal for both immune and non-immune serum (Table 1). Serum from infected animals (first challenge and re-challenge) did not stimulate lymphocyte proliferation in vitro to a greater extent than non-immune serum (data not shown).

\section{Discussion}

The present in vitro results indicate that, despite previously shown opsonizing effects of serum for phagocytosis (Verburg van Kemenade et al., 1994), carp serum contains 

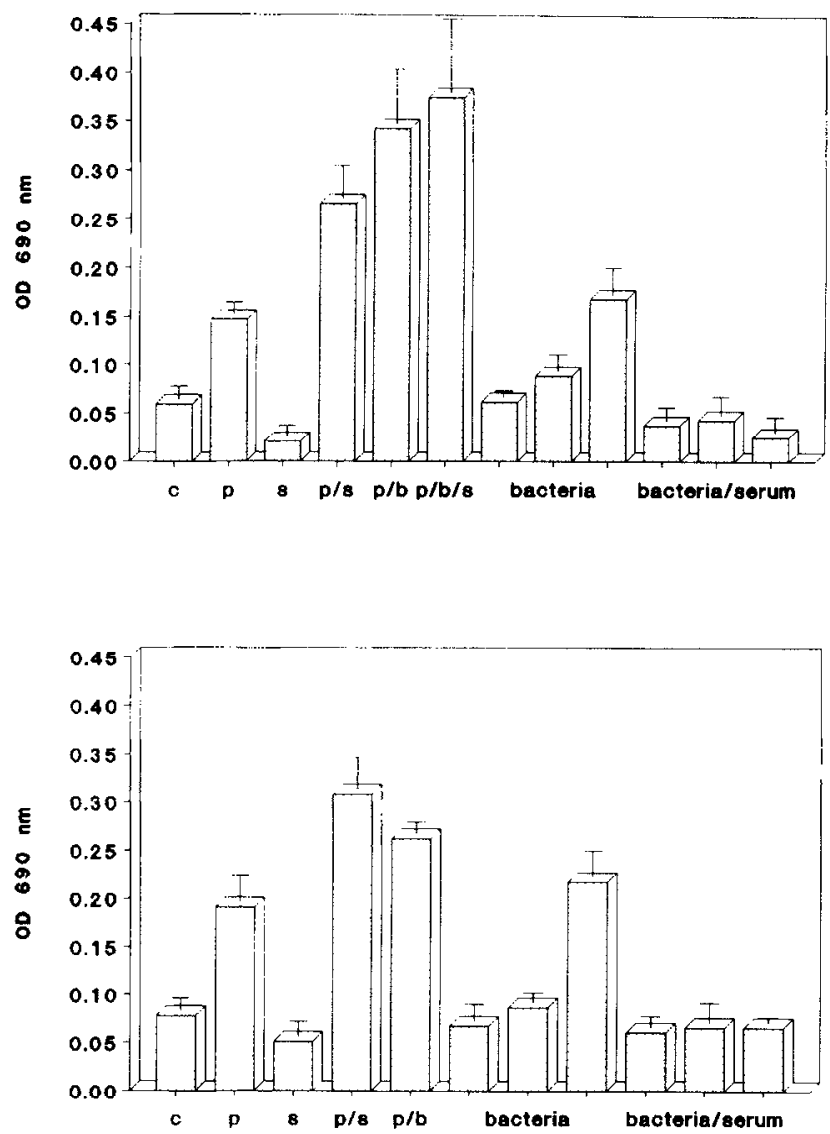

Fig. 5. Effect of pooled carp serum on NBT reduction in A. salmonicida stimulated macrophage-(a) and neutrophilic granulocyte (b) cell fractions. c. Control incubation; $p$, stimulation with $0.1 \mu \mathrm{g} \mathrm{m}^{-1} \mathrm{PMA} ; \mathrm{s}$, incubation with $5 \% \mathrm{v} / \mathrm{v}$ PCS; $\mathrm{p} / \mathrm{s}$, combined incubation with PMA and serum; $\mathrm{p} / \mathrm{b}$. combined incubation of $\mathrm{PMA}$ and $10^{10}$ A. salmonicida bacteria $\mathrm{ml}^{-1} ; \mathrm{p} / \mathrm{b} / \mathrm{s}$, incubation in the presence of PMA, bacteria and serum; bacteria, incubation with $10^{8}, 10^{9}$ and $10^{10}$ bacteria $\mathrm{ml}^{-1}$; bacteria/serum, incubation with $10^{8}, 10^{9}$ and $10^{10}$ bacteria $\mathrm{ml}^{-1}$, in the presence of $5 \% \mathrm{v} / \mathrm{v}$ PCS. Values represent means $\pm \mathrm{SD}$ of quadruplicate measurements.

factors that are inhibitory to the basal respiratory burst activity of both macrophages and neutrophilic granulocytes. This would imply that under normal conditions phagocytic cells are under a continuous inhibition by serum factors, a phenomenon that could prevent these cells from secreting factors that could damage tissue through the induction of inflammatory reactions. However. PMA stimulation of the respiratory burst reaction. in combination with serum. induced a synergistic stimulation of the respiratory burst reaction. These results indicate that besides inhibitory factors, carp serum also contains stimulatory factors. This would enable phagocytic cells to react efficiently to stimulatory factors transferred through the phosphatidyl-inositol pathway. The serum factors could possibly facilitate calcium mobilization, inducing a synergistic stimulus through calcium and diacylglycerol. The presence of yet unidentified macrophage respiratory burst 
inhibitory factors in serum has earlier been found for mouse peritoneal macrophages (Walker et al., 1991). Culture of the macrophages in serum-free medium induced significant activation of respiratory burst activity.

Although the presence of macrophage activating and inhibitory factors in serum of fish can be expected, they have not yet been extensively identified. In rainbow trout a lymphocyte-derived macrophage-activating factor has been identified, which has many characteristics of interferon- $\gamma$. Additionally a migration-inhibiting factor and a chemotactic factor were found. In carp, granulocyte-macrophage colony stimulating factor (gmCSF) is postulated (reviewed by Secombes, 1991).

We currently find that supernatant from cultured PHA pre-activated carp lymphocytes contains macrophage- and granulocyte-activating factors, thus it can be postulated that these serum factors may at least be partly lymphocyte-derived. Analogous to the results obtained in trout (Graham and Secombes, 1988, 1990), an interferon- $\gamma$-like factor may be involved. From the initial increase in respiratory burst activity when administering two-fold dilutions of lymphocyte supernatant, it is suggested that these culture supernatants probably contain both inhibitory and stimulatory components. Since heat treatment was ineffective in neutralizing the inhibitory or stimulatory serum factors it is likely that complement factors are not involved.

The present results show that macrophages and neutrophilic granulocytes from carp can be rapidly induced to high respiratory burst activity and to rapidly killing of atypical A. salmonicida bacteria. As reported previously for the respiratory burst activity (Verburg van Kemenade et al., 1994), we now confirm that the granulocytes of carp have more potent microbicidal activity than macrophages.

The absence of a synergistic stimulation by serum factors and atypical A. salmonicida, and the additional stimulatory effect of PMA and these bacteria, suggests that activation of the respiratory burst by $A$. salmonicida is not induced through stimulation of the phosphatidyl-inositol pathway.

Immune serum from carp that had survived a sub-lethal infection with $A$. salmonicida did not contain increased levels of stimulatory factors, compared with non-immune serum. This implies that, during the disease process and sustained protection, additional activation of the aspecific response by soluble serum factors is not to be expected. This conclusion is strengthened by the lack of a clearly enhanced respiratory burst activity, or enhanced PMA sensitivity, or macrophages or granulocytes during infection. In rainbow trout, however, head kidney cells showed enhanced levels of in vitro produced macrophage-activating factor after immunization with formalin killed A. salmonicida and lymphocytes were more active in in vitro proliferation. These effects remained present for at least 5 weeks (Marsden et al., 1994).

Although the present results do not indicate that protection of carp upon rechallenge with $A$. salmonicida occurs via a systemic up-regulation of macrophage or neutrophilic granulocyte respiratory burst activity, it cannot be excluded that at local sites up-regulation might be more prominent. The detrimental effects of A. salmonicida on phagocytes, which have been reported for trout (Olivier et al., 1992), and which are also seen in carp (unpublished data), might however, render this impossible.

We have demonstrated that fish macrophages and granulocytes undergo a multiple regulation, which in mammals has been shown to enable the cells to undergo a selective 
stimulation of respiratory burst activity, secretion of inflammatory factors, or production of $\mathrm{T}$ cell stimulating cytokines. In fish also, similar serum factors might play an important role in this regulation. Elucidation of the role that fish cytokines have in the stimulation or inhibition of the macrophage, and characterization of the macrophage secretion products, will enable further research on macrophage functions in the regulation of the (a) specific immune response.

\section{References}

Bayne, C.J., 1986. Pronephric leucocyles of Cyprinus carpis: Isolation, separation and characterization. Vet. Immunol. Immunopathol., 12: 141-151.

Bootsma, R., Fijan, N. and Blommaert, J., 1977. Isolation and identification of the causative agent of carp erythrodermatitis. Veterinarski Archiv., 47: 291-302.

Daly, J.G., Wiegertjes, G.F. and van Muiswinkel, W.B.. 1994. Protection against carp erythrodermatitis following bath or subcutaneous exposure to sublethal numbers of virulent Aeromonas valmonicida subsp. nova. J. Fish. Dis., 17: 67-75.

Evenberg, D., Versluis, R. and Lugtenberg B., 1985. Biochemical and immunological characterization of the cell surface of the fish pathogenic bacterium Aeromonas valmonicida. Biochem. Biophys. Acta, 815 : $233-244$.

Graham, S. and Secombes, C.J., 1988. The production of a macrophage-activating factor from rainbow Salmo gairdneri leucocytes. Immunology, 65: 293-297.

Graham, S. and Secombes, C.J., 1990. Do fish leucocytes secrete interferon- $\gamma^{\prime}$ ? J. Fish Biol., 36: 563-573.

Graham, S., Jeffries, A.H., and Secombes. C.J., 1988. A novel assay to detect macrophage bactericidal activity in fish: factors influencing the killing of Aeromonas salmonicida. J. Fish Dis., 11: 389-396.

Marsden, M.J., Cox, D. and Secombes, C.J., 1994. Antigen-induced release of macrophage activating factor from rainbow trout Oncorhynchus mykiss leucocytes.. Vet. Immunol. Immunopathol., 42: 199-208.

McCarthy, D.H. and Roberts, R.J., 1980. Furunculosis of fish - the present state of our knowledge. In: M.A. Droop and H.W. Jannasch, (Editors), Advances in Aquatic Microbiology. Academic Press, London, pp. $293-341$.

Olivier, G., Moore, A.R. and Fildes, J., 1992. Toxicity of Atromonas salmonicida to atlantic salmon Salmo salar peritoneal macrophages. Dev. Comp. Immunol.. 16: 49-61.

Pick, E. and Mizel, D., 1981. Rapid microassays for the measurement of superoxide and hydrogen peroxide production by macrophages in culture using an automatic enzyme immunoassay reader. J. Immunol. Methods, 46: $211-226$.

Secombes, CI. 1991. The phylogeny of rytokines. In A.W. Thomson (Editor), The Cytokine Handhook. Academic Press, London, pp. 387-412.

Temmink, J.H.M. and Bayne, C.J., 1987. Ultrastructural characterization of leucocytes in the pronephros of carp (Cyprinus carpio, L.). Dev. Comp. Immunol., 11: 125-137.

Verburg-van Kemenade, B.M.L., Groeneveld, A., Van Rens, B.T.T.M. and Rombout, J.H.W.M., 1994. Characterization of macrophages and neutrophilic granulocytes from the pronephros of carp (Cyprinus (arpio). J. Exp. Biol., 187: 143-158.

Walker, L.. Lowrie, D.B., Barclay, R., Dixon, G., Saunders, K. and Andrew, P.W.. 1991. Activation of mouse peritoneal macrophages by maintenance in serum-free medium. Immunology, 73: 109-113.

Yano, T., Ando. H. and Nakao, M., 1984. Optimum conditions for the assay of hemolytic complement titer of carp and seasonal variation of the titers. J. Fac. Agric. Kyushu Univ., 29: 91-101. 